\title{
Mapping wetland changes in China between 1978 and 2008
}

\author{
NIU ZhenGuo ${ }^{1 *}$, ZHANG HaiYing ${ }^{1}$, WANG XianWei ${ }^{1}$, YAO WenBo ${ }^{2}$, ZHOU DeMin $^{3}$, \\ ZHAO KuiYi ${ }^{4}{ }^{2}$ ZHAO Hui ${ }^{1}$, LI NaNa ${ }^{1}$, HUANG HuaBing ${ }^{1}$, LI CongCong ${ }^{5}$, YANG Jun ${ }^{6}$, \\ LIU CaiXia ${ }^{1}$, LIU Shuang ${ }^{1}$, WANG Lin $^{1}$, LI Zhan ${ }^{1}$, YANG ZhenZhong ${ }^{5}$, QIAO Fei ${ }^{1}$, \\ ZHENG YaoMin ${ }^{1}$, CHEN YanLei $^{7}$, SHENG YongWei ${ }^{8}$, GAO XiaoHong ${ }^{9}$, ZHU WeiHong ${ }^{10}$, \\ WANG WenQing ${ }^{11}$, WANG Hong ${ }^{12}$, WENG YongLing ${ }^{13}$, ZHUANG DaFang ${ }^{14}$, LIU JiYuan ${ }^{14}$, \\ LUO ZhiCai ${ }^{15}$, CHENG Xiao ${ }^{5}$, GUO ZiQi ${ }^{1}$ \& GONG Peng ${ }^{1,2,7^{*}}$
}

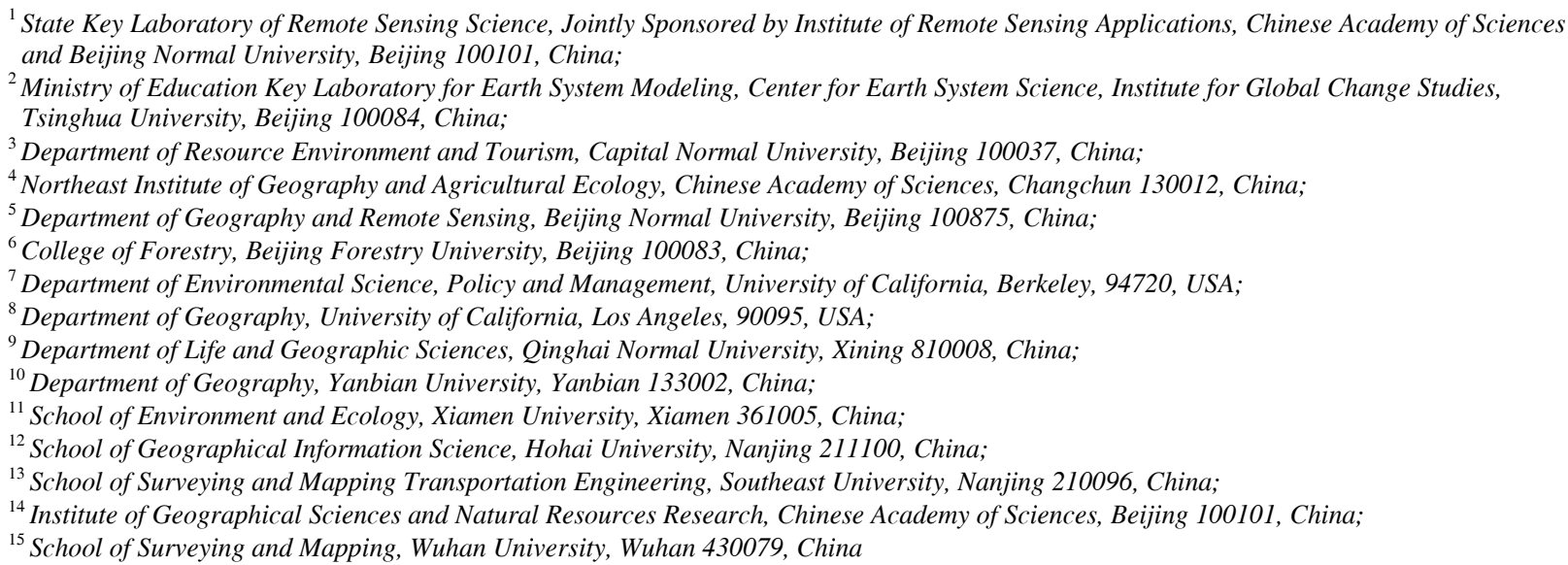

Received December 26, 2011; accepted February 16, 2012; published online April 12, 2012

Four wetland maps for all China have been produced, based on Landsat and CBERS-02B remote sensing data between 1978 and 2008 (1978, 1990, 2000 and 2008). These maps were mainly developed by manual interpretation and validated by substantial field investigation in 2009. Based on these maps, we analyzed the 2008 wetland distribution in China and discussed wetland changes and their drivers over the past 30 years. (i) There were about $324097 \mathrm{~km}^{2}$ of wetlands in 2008 , for which inland marshes or swamps were the most common wetland type (35\%), with lakes (26\%) second. Most of the wetlands were in Heilongjiang, Inner Mongolia, Qinghai and Tibet, occupying about 55\% of the national wetland area. (ii) From 1978 to 2008, China's wetland area continually and significantly decreased, by about $33 \%$ based on changes in the wetland map. This was in sharp contrast to the increase in artificial wetlands, which increased by about $122 \%$. Inland marshes accounted for the main loss of total wetlands from 1978 to 2000. From 2000 through 2008, riverine and lacustrine wetlands constituted the main wetland loss. Fortunately however, the rate of wetland loss decreased from 5523 to $831 \mathrm{~km}^{2} / \mathrm{a}$. (iii) The change ratio of lost natural wetlands (including inland and coastal wetlands) to non-wetlands has decreased slightly over the past 30 years. From 1978 to 1990, nearly all natural wetlands (98\%) lost were transformed into non-wetlands. However, the ratio declined to $86 \%$ from 1990 to 2000, and to $77 \%$ from 2000 to 2008. (iv) All Chinese provinces were divided into three groups according to patterns of wetland changes, which could relate to the driving forces of such changes. Tibet was completely different from other provinces, as it was one representative example in which there was a net wetland increase, because of global warming and decreased human activity since 1990. Increased economic development caused considerable wetland loss in most eastern provinces, and artificial wetlands increased.

wetland change, remote sensing, global change, China, wetland reserves

Citation: $\quad$ Niu Z G, Zhang H Y, Wang X W, et al. Mapping wetland changes in China between 1978 and 2008. Chin Sci Bull, 2012, 57: 2813-2823, doi: $10.1007 / \mathrm{s} 11434-012-5093-3$

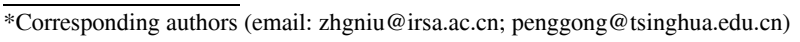


Wetlands are among the world's most productive environments, and provide a wide variety of benefits. They are cradles of biological diversity, providing water and primary productivity upon which countless species of plants and animals depend for survival [1].

Much wetland research has been conducted in China since the 1950s. However, this research is mainly focused on exploitation rather than protection of marshland, especially on the Northeast China Plain. Until the present, this region has been made up of about one-fifth marshland [2]. Over the past 30 years, China has made considerable economic advances, accompanied by environmental degradation [3]. Disappearing natural wetland is one potential environmental danger confronted by the country [3]. Already becoming aware of this environmental degradation, China is increasingly assuming responsibilities on the world stage by participating in environmental treaties, one of which is the Ramsar Convention, which the Chinese government joined in 1992. To protect biodiversity, the government had created almost 2000 nature reserves by the end of 2003 (mostly during the foregoing 20 years) [4], plus many zoos, museums, botanical gardens, wildlife breeding centers, and gene and cell banks. The reserves cover $14.4 \%$ of China's territory, a percentage higher than the world average and those of most developed countries.

Until 2009, more than 550 wetland reserves were created in China, among which 37 have been included in the Ramsar List of Wetlands of International Importance. From 1995 to 2003, the State Forestry Administration did a detailed national statistical survey of lakes, bogs, rivers, coastal wetlands, and reservoirs larger than $1 \mathrm{~km}^{2}$. However, there was no wetland geographic map for public use, hindering our understanding of spatial distribution and wetland changes across the country.

To aid avian flu modeling research in the country, we have completed the only comprehensive China wetland map, based on Landsat TM images in 1990 and 2000 and manual interpretation [5-7]. We then completed the newest wetland map using CBERS-02B charge-coupled device (CCD) images acquired around 2008. Using a cross-validation method, we also updated the wetland maps of 1990 and 2000 based on 2009 field investigations across China. Then, based on Landsat Multispectral Scanner (MSS) data from 1978, a China wetland map for that period was developed by the same research group in the Chinese Academy of Sciences.

In this paper we discuss the following: (i) What is the Chinese wetland situation? (ii) What is the extent and location of wetland changes during the past 30 years? (iii) What are the main drivers of wetland change and the potential consequences of these changes?

\section{Data and methods}

\subsection{Wetland classification system}

To meet the requirements of wetland maps, a preliminary classification was suggested (Table 1) [5,6], which is a combination of the Ramsar Convention and classification of the Chinese Forest Administration Bureau. This was revised based on remote sensing to make it more practical. The first level of this classification is identical to the Ramsar Convention, to facilitate comparison of wetland distribution among different countries. However, the second level is highly simplified, to make the scheme more operational during national wetland mapping using remote sensing. However, rivers and floodplains were merged as river wetlands during wetland change analysis, because they usually transformed into each other. In addition, artificial wetlands and coastal wetlands retained their first level classification instead of second level classification, after consideration of their overall minor differences.

\subsection{Data and methods}

Image data used for the China wetland map of 1990 and 2000 were obtained from the University of Maryland (http:// glcf.umiacs.umd.edu/data/2007). These are composed of around 597 Landsat scenes covering all of China at one time [6]. The CBERS-02B data were downloaded from the China Resources Satellite Application Center, which stitched together up to 1400 scenes to cover all China, given its smaller scene width $(113 \mathrm{~km})$. Compared with image composites with Thematic Mapper (TM) bands 5, 4, and 3 as optimal settings for wetland mapping [5], the combination of CBERS02B CCD bands 4, 3 and 2 were used during the manual interpretation. Besides the image data, other reference data for China, such as digital elevation (GTOPO 30), the land use/cover map for the year $2000(1: 100000)$, images from Google Earth and its visualization tool sets were used to verify and validate the laboratory results. The CBERS CCD images were registered based on a 1990s TM image, and the geo-registration error was constrained to within two pixels (as measured by root mean square error).

The CBERS CCD image interpretation method, in which a semi-automated procedure was adopted for time-saving, is different from that of the Landsat TM image; the latter was completely manually interpreted. Wetland water bodies of every type were first classified using the Feature Analyst software, and then identified one by one according to the image and compared with the previous map. In the second step, the other wetland types were still interpreted manually based on the 1990 wetland map. Finally, after validation, all wetland types were merged.

More field investigation and cross-validation were done during the new wetland mapping. Six representative regions, including the Qinghai-Tibet Plateau, the Northeast Plain, the Yellow River delta, Dongting and Poyang Lakes, Jiangsu coastal wetland and southeast mangrove wetland, were selected for the field investigation during July and August 2009. More than 10000 photos were collected to validate the 2008 wetland map. 
After validation of the latter map, the three maps were intersected and a cross-table of change between every twoperiod wetland type was constructed. According to the change model of wetland types between different periods, we identified impossible changes, such as from coastal wetlands to inland wetlands, and re-checked the images to revise the corresponding map. Auxiliary materials and literature related to wetland distribution were collected to validate regions we could not confirm during the manual interpretation. The Google Earth information was also used. The approach was used continually during the interpretation and validation processes.

The development method of the wetland map in 1978 was similar to that of the 1990 map, primarily through manual interpretation with cross-referencing of the 1990 wetland map.

\subsection{Data comparison methods}

The variable spatial resolutions of the different satellite images used for the map of each period inevitably introduce new errors during result comparison. To avoid these problems, we used windows filtering based on results (Figure 1). Interpretation results were first rasterized according to corresponding spatial resolution of the satellite image. Then, different window size filtration was done, and resultant raster maps at $240 \mathrm{~m}$ resolution were produced. In each filtration window, only the wetland type whose area equals that of the window can be retained. The window moved one by one (not by pixels) during the recalculation, and the last row and line were discarded. The wetland area of the resultant map would obviously be less than the area of the original after these calculations, because substantial minor wetland patches are ignored. Only the total wetland area in 2008 was based on the original map in the following, to describe the recent wetland situation. The other wetland change analysis was based on the resultant map.

\section{Results}

\subsection{Recent wetland situation}

The total national wetland area was about $324097 \mathrm{~km}^{2}$ in 2008 , within which inland wetland was the most common wetland type, occupying about $85 \%$ of all wetland area. Artificial wetland area was about $12 \%$ (Figure 2). Inland marshes/swamp, which include riverine, lacustrine and palustrine wetlands, were the most common types among the inland wetlands, occupying an area of about $11385 \mathrm{~km}^{2}$ or $35 \%$ of national wetland area. Reservoirs/pools were about $23697 \mathrm{~km}^{2}$ in area and were the most widely distributed type among artificial wetlands. However, coastal wetland area, for which shallow sea water area to $6 \mathrm{~m}$ depth at low tide is not included, was only about $10035 \mathrm{~km}^{2}$.

Most wetlands were in Heilongjiang, Inner Mongolia, Qinghai and Tibet, with total area about $177800 \mathrm{~km}^{2}$, or about $55 \%$ of national wetland. Xinjiang, Jiangsu and Jilin were second, with total wetland area $16 \%$. The wetland area of Hubei Province, which is known as the "province of a thousand lakes", had about $8030 \mathrm{~km}^{2}$, only $2.48 \%$ of the national area. Because of agricultural development for thousands of years, especially over the last 30 years, there is almost no natural wetland in the plains of Eastern China.

All coastal wetlands are located in Eastern China, including Liaoning, Hebei, Shandong, Tianjin, Jiangsu, Shanghai, Zhejiang, Fujian, Guangdong, Guangxi, Hainan, Taiwan, Hong Kong and Macao. Wetlands in the north of Hangzhou have sandy or muddy bottoms, except the rocky ones on the Liaoning and Shandong peninsulas, which are very different from those in southern Hangzhou Bay. The wetland area in northern Hangzhou Bay was about $5863 \mathrm{~km}^{2}$, or $60 \%$ of all coastal wetlands. However, most coastal wetlands were in Liaoning (18\%), Shandong (30\%), Jiangsu (16\%) and Fujian $(15 \%)$.

Among the coastal wetlands, estuarine water, tidal zone/ beach and coastal marshes are the most common types,

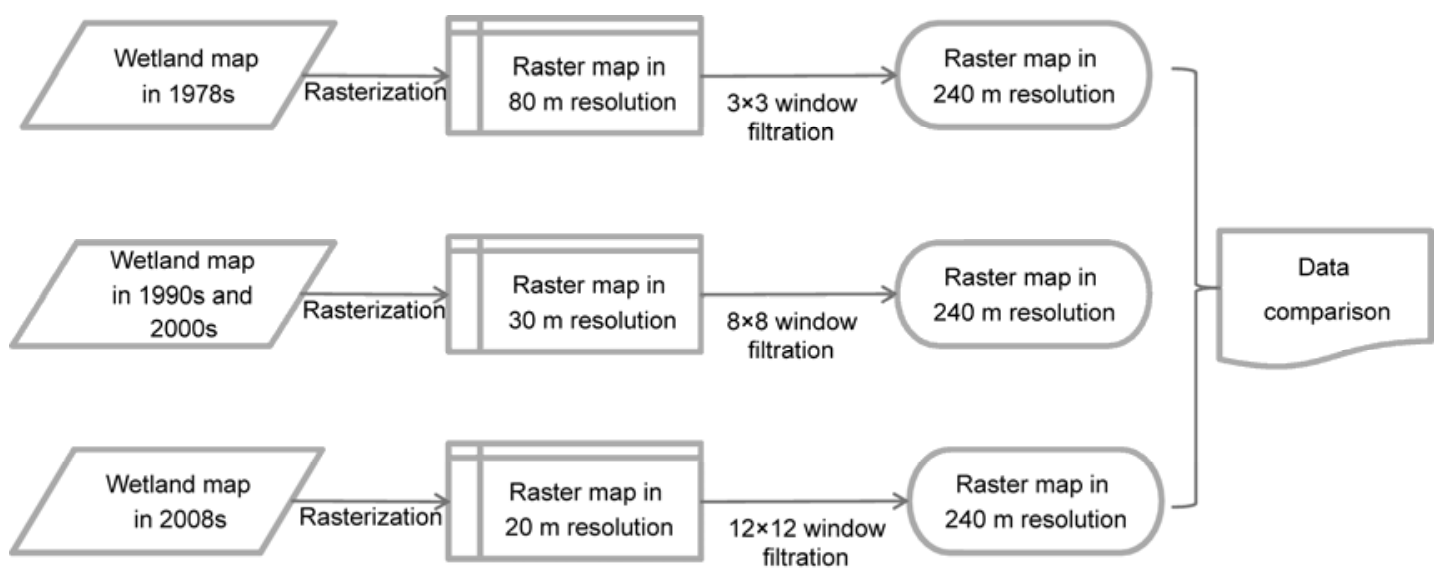

Figure 1 Data comparison scheme. 


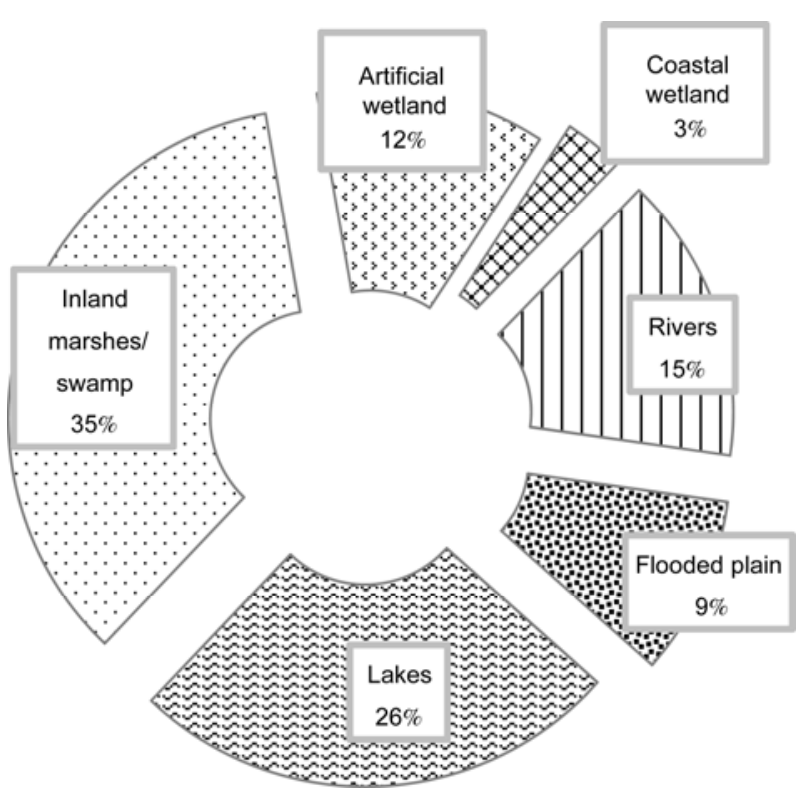

Figure 2 China wetland distribution in 2008.

occupying $51 \%, 28 \%$ and $20 \%$, respectively. Estuarine water, as a very important fish habitat, is very difficult to distinguish from river and shallow water in Landsat TM and CBERS images. So the area of estuarine water is much more uncertain and, according to our estimations, its area also should not be changed so quickly in recent years.

\subsection{Characteristics of wetland change}

(1) General trends of wetland change. From 1978 to 2008 according to the interpretation map, China's total wetland area continually and strongly decreased, from $309296 \mathrm{~km}^{2}$ in 1978 to $207897 \mathrm{~km}^{2}$ in 2008 (Figure 3). However, the

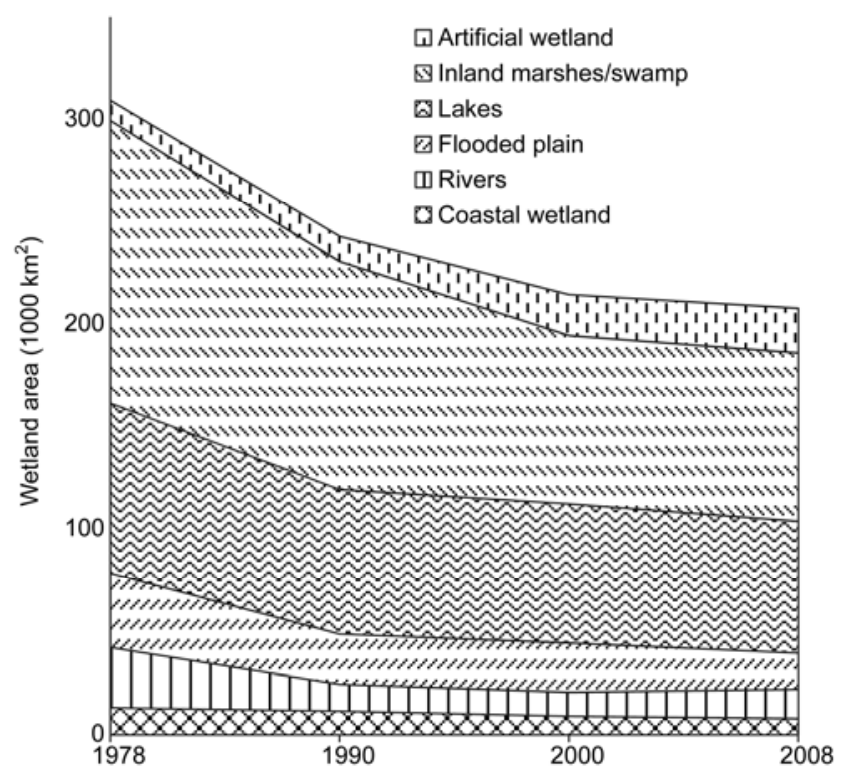

Figure 3 Wetland changes from 1978 to 2008 in China. rate of decrease, which was $5523 \mathrm{~km}^{2} / \mathrm{a}$ from 1978-1990, $2847 \mathrm{~km}^{2} / \mathrm{a}$ from $1990-2000$, and $831 \mathrm{~km}^{2} / \mathrm{a}$ from 2000-2008, slowed greatly. The possible reason is that there is no more available wetland to be exploited in developed Eastern China, and hostile environments in sparsely populated Western China impede wetland exploitation. Another reason is stricter protection of wetland reserves, because of the Chinese government's greatly enhanced awareness of environmental importance in recent years.

Inland marshes/swamp, one of the most important wetland types, had similar change trends as total wetlands. This type decreased tremendously, by $19.46 \%$ and $26.05 \%$ during the periods 1978-1990 and 1990-2000, respectively. However, it stabilized between 2000 and 2008.

Frequent water level changes lead to increased uncertainties in floodplain identification, especially for distinguishing from rivers. Thus, floodplains and rivers were grouped as river wetlands during the wetland change analysis. From Table 1, we see that river wetlands and lakes decreased significantly from 1978 to 1990 , and continued to decrease considerably from 1990 to 2008 .

(2) Characteristics of wetland type change. When coastal wetlands and inland wetlands were grouped as natural wetlands, we found that the natural wetland area continually and strongly decreased over the past 30 years, from $299504 \mathrm{~km}^{2}$ in 1978 to $186152 \mathrm{~km}^{2}$ in 2008 . In contrast, there was a continual increase in artificial wetland, from $9793 \mathrm{~km}^{2}$ (in 1978) to $21745 \mathrm{~km}^{2}$ (in 2008) (Figure 4). Because the biodiversity of natural wetlands is much greater than artificial wetlands, more attention should be paid to the serious decrease of natural wetlands.

From Figure 4, we find that nearly all lost natural wetlands (98\%) were converted to non-wetlands before 1990. The conversion ratio then gradually dropped, to $86 \%$ from 1990 to 2000 , and to $77 \%$ after 2000 . This likely indicates that agricultural exploitation chiefly contributed to the lost wetlands during early periods, and more artificial wetlands were converted from natural wetlands in subsequent periods.

(3) National patterns of wetland changes. Similar to the uneven spatial distribution of wetland in China, wetland changes between provinces varied greatly from 1978 to 2008, accompanied by rapid social and economic development (Table 2). The majority of the wetland changes were in provinces with the most wetlands, such as Heilongjiang, Inner Mongolia and Tibet. In addition to the provincial variations, the directions of wetland change were also not identical over the different periods after 1978. Changes in wetland direction and amount potentially give a comprehensive overview that reflects various characteristics of natural environment and social economy in those provinces.

Ward hierarchical clustering was used based on the results of wetland change among provinces (Table 2) to study the spatial characteristic of this change. Three groups that included the northwest region (Xinjiang, Qinghai and Tibet), northeast region (Inner Mongolia and Heilongjiang) and the 
Table 1 Summary of wetland area across different periods in China (area in $\left.\mathrm{km}^{2}\right)^{\mathrm{a})}$

\begin{tabular}{|c|c|c|c|c|c|}
\hline \multirow{2}{*}{ Type } & \multirow{2}{*}{ Subtype } & \multirow{2}{*}{ Wetland area in 1978} & \multicolumn{3}{|c|}{ Wetland changes } \\
\hline & & & $1978-1990$ & $1990-2000$ & 2000-2008 \\
\hline \multirow{6}{*}{ Coastal wetland } & Tide zone/shallow beach & 3399 & 1014 & -1202 & -1368 \\
\hline & Marine marshes/mangrove & 4363 & -2297 & -810 & 254 \\
\hline & Estuarine water & 4987 & -517 & -328 & 21 \\
\hline & Estuarine delta & 140 & 178 & 37 & -66 \\
\hline & Lagoons & 215 & -19 & -51 & -60 \\
\hline & Sum & 13104 & -1641 & -2355 & -1218 \\
\hline \multirow{4}{*}{ Inland wetland } & River wetlands $^{\text {b) }}$ & 65293 & -27936 & -1955 & -3779 \\
\hline & Lakes & 82903 & -12463 & -2609 & -3436 \\
\hline & Inland marshes/swamp & 138203 & -26894 & -28995 & -70 \\
\hline & Sum & 286400 & -67293 & -33559 & -7285 \\
\hline \multirow{5}{*}{ Artificial wetland } & Reservoirs/ponds & 5157 & 212 & 5338 & 1780 \\
\hline & Artificial channel & 616 & -521 & 140 & 125 \\
\hline & Seawater fish farms/salt flats & 3984 & 2976 & 1966 & -42 \\
\hline & Other wetlands ${ }^{\mathrm{b})}$ & 35 & -6 & -5 & -12 \\
\hline & Sum & 9793 & 2661 & 7439 & 1851 \\
\hline Total area & & 309297 & -66273 & -28475 & -6652 \\
\hline
\end{tabular}

a) Summary table is based on change of wetland map according to methods described in Figure 1. A positive value means wetland area increase, negative value means wetland area decrease. b) We combined floodplain with rivers as river wetlands, landscaping and recreational water bodies and others as other wetlands.

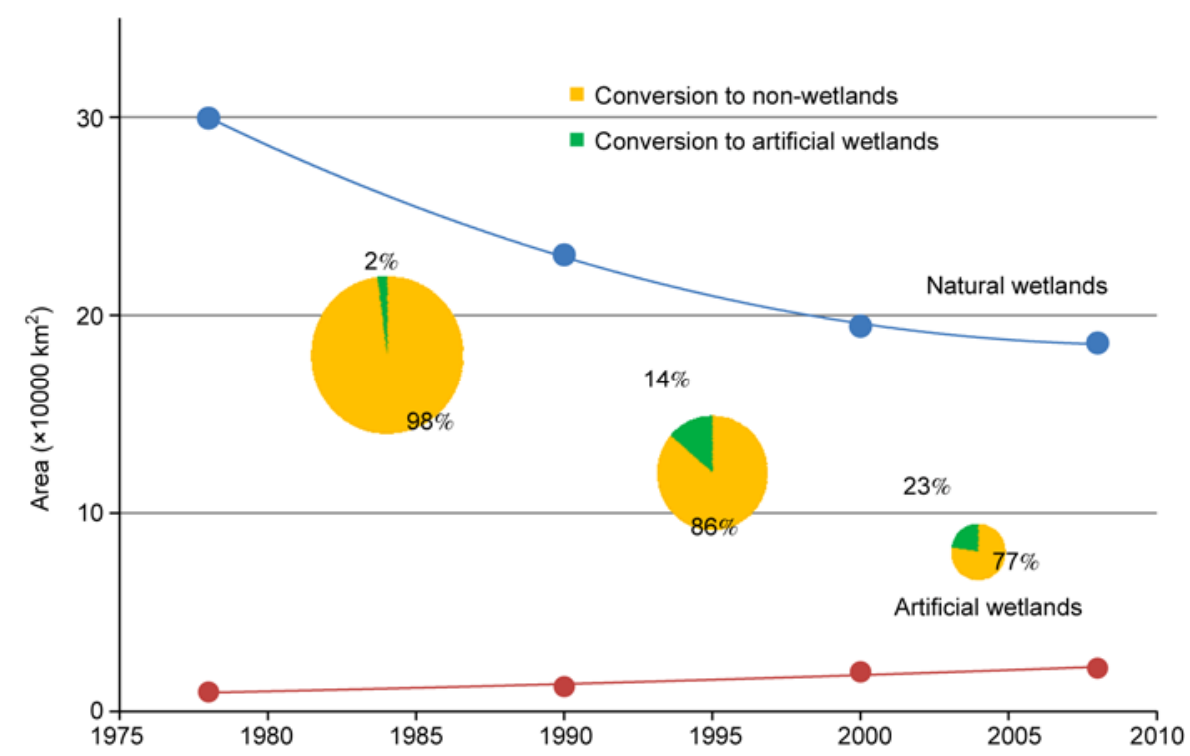

Figure 4 Wetland type conversions in China.

other provinces were then derived, according to Figure 5. This spatial characteristic of wetland change was first determined by the spatial pattern of wetland distribution, in which most wetlands are located in the northwest and northeast regions [5]. Wetlands decreased greatly in the northeast, in contrast to a slight increase in the northwest. The other provinces, with less wetland and small areal change, are grouped as one.
There are different wetland change characteristics in every region, because of various drivers. Taking the northwest region as an example, wetlands greatly decreased before 1990 and slightly increased between 1990 and 2000. However, wetlands greatly increased in Tibet after 2000, in contrast to the slight wetland decrease in Xinjiang and Qinghai. For the northeast region, though there was a large wetlands decrease in Heilongjiang and Inner Mongolia, 
Table 2 Wetland changes from 1978 to 2008 (area in $\mathrm{km}^{2}$ )

\begin{tabular}{|c|c|c|c|c|c|c|c|c|c|}
\hline & & \multicolumn{3}{|c|}{ Wetland changes } & & & \multicolumn{3}{|c|}{ Wetland changes } \\
\hline & & $1978-1990$ & 1990-2000 & 2000-2008 & & & 1978-1990 & 1990-2000 & 2000-2008 \\
\hline \multirow{2}{*}{ (1) } & Heilongiiang & -9808 & -13766 & -1325 & \multirow{17}{*}{ (3) } & Hunan & -2094 & 401 & -1416 \\
\hline & Inner Mongolia & -11347 & -7771 & -2479 & & Sichuan & -2203 & -65 & -755 \\
\hline \multirow{3}{*}{ (2) } & Xinjiang & -8609 & 564 & -160 & & Hubei & -883 & -189 & -1832 \\
\hline & Qinghai & -9601 & 337 & -1855 & & Jiangxi & -206 & -1260 & -813 \\
\hline & Tibet & -6380 & 1674 & 4387 & & Jilin & -3701 & -5166 & 866 \\
\hline \multirow{12}{*}{ (3) } & Hebei & -242 & -755 & 129 & & Liaoning & -1978 & -393 & -220 \\
\hline & Gansu & -1436 & -585 & -97 & & Chongqing & -351 & -49 & 98 \\
\hline & Beijing & 23 & -30 & -70 & & Shanghai & -169 & -278 & -36 \\
\hline & Shanxi & -329 & -50 & -38 & & Yunnan & -565 & 76 & -146 \\
\hline & Tianjin & 104 & 104 & -275 & & Guizhou & -202 & 25 & 4 \\
\hline & Zhejiang & -943 & 5 & 63 & & Fujian & -775 & 170 & -420 \\
\hline & Shaanxi & -588 & -306 & -28 & & Taiwan & -483 & 2 & -102 \\
\hline & Jiangsu & -619 & 28 & -334 & & Guangxi & -1112 & 140 & -230 \\
\hline & Shandong & 1239 & -740 & 682 & & Guangdong & -895 & -60 & -67 \\
\hline & Anhui & -980 & -93 & -514 & & Hong Kong & -32 & 2 & 0 \\
\hline & Henan & -425 & -236 & 101 & & Macao & 8 & -1 & 2 \\
\hline & Ningxia & -340 & -273 & 50 & & Hainan & -350 & 61 & -122 \\
\hline
\end{tabular}

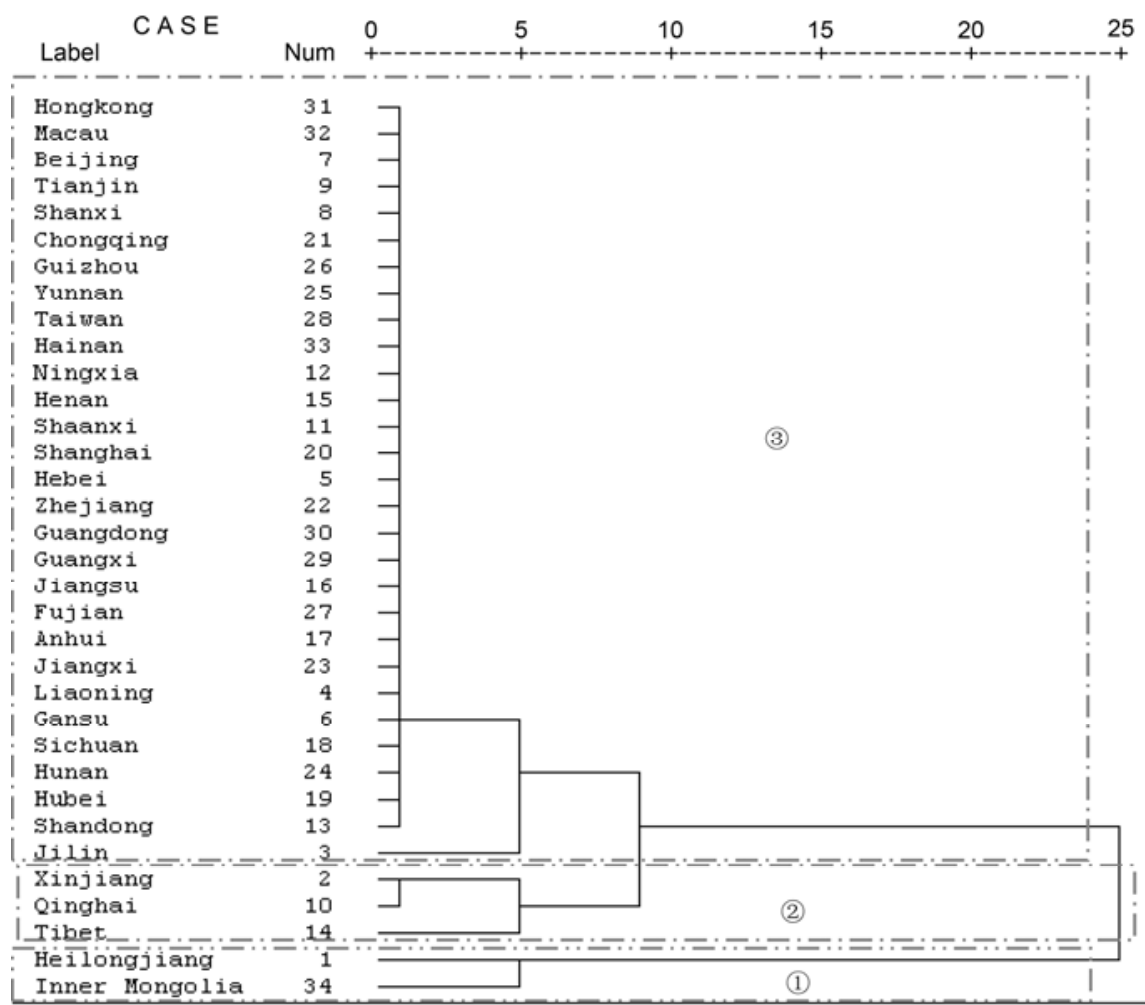

Figure 5 Cluster dendrogram of wetland change.

most wetlands were lost between 1990 and 2000 in Heilongiiang, whereas losses occurred before 1990 in Inner Mongolia. The same phenomenon of wetland decrease was observed in the other provinces, where there was reduced wetland because of a long history of agricultural development.

(4) Comparison of wetland change since 2000 and earth surface quality change since 2003, across China. Data from GRACE (Gravity Recovery and Climate Experiment) 
were used to analyze surface quality changes. These changes in the Chinese mainland were then reversed by a combination of Fan filtering and decorrelation filtering (P3M6) [8], based on gravity field model CSR RL04 from January 2003 to December 2010. Equivalent water height was used to represent surface quality change that may be mainly caused by ground and surface water quality changes. Water has accumulated in the following areas between 2003-2010: Northern Tibet, the Three Gorges Reservoir area, most of Jiangxi, southern Anhui, northwest Fujian, western Zhejiang, and the Qaidam Basin (Figure 6). There was a downward trend of earth surface quality mainly in southeast Tibet, followed by most areas in Shanxi, Hebei and Inner Mongolia; northern regions of Xinjiang had a small decreasing trend. Trends in other parts of the earth surface quality change are not so obvious. These changes have a certain relationship with the wetland changes shown in Table 2. Wetlands in Tibet, Qaidam Basin, and Chongqing also increased over the same period. Water storage of the Three Gorges was strongly reflected in the GRACE data. However, the increasing trend of water quality in southern Jiangxi and Anhui does not correspond well with wetland changes, which requires further study. Since the wetlands in North China constitute too small an area, the decrease of surface quality may be related to the region's numerous coal mines and groundwater mining. Drastic reduction of water in southeast Tibet, which is clearly not conducive to wetland development, may be related to a large number of glacial meltwater outflows through the Brahmaputra Valley. The change in this area is also reflected in the following analysis on lake water level changes. The reason for water reduction in Xinjiang will be described in the following analysis.

\section{Driving forces of wetland changes}

Water is no doubt fundamental to wetlands. In addition to human development and use, the water balance determines the growth and decline of wetlands. Therefore, human factors (such as direct development of wetlands and water use from wetlands by humans) and natural factors (such as glaciers/ice/snowmelt, precipitation, and evapotranspiration) are considered in the following analysis.

\subsection{Relationship between wetlands and climate change}

Climate elements as background for wetland change, which are mainly manifest through temperature and precipitation, influence the growth and decline of wetlands. First, increased precipitation undoubtedly expands wetland, i.e. precipitation has a positive correlation with wetlands. In contrast, the temperature effect on wetland is more complex. Rising temperatures increase evaporation, accelerating loss of water in wetland, so wetland area shrinks. However, where there are glaciers and snow accumulation in valleys, rising temperatures increase meltwater, and the increased runoff expands lakes and wetlands. Therefore, in terms of wetlands, temperature change in different regions will have varying impacts.

From 1978 until the present, Chinese regions have had warming trends, in average annual temperature, average maximum temperature, or average minimum temperature. This is especially true in northern areas, including northern reaches of North, Northeast and Northwest China [9]. The Qinghai-Tibet Plateau also has had a warming trend [10]. A turning point of temperature occurred in the mid 1980s,

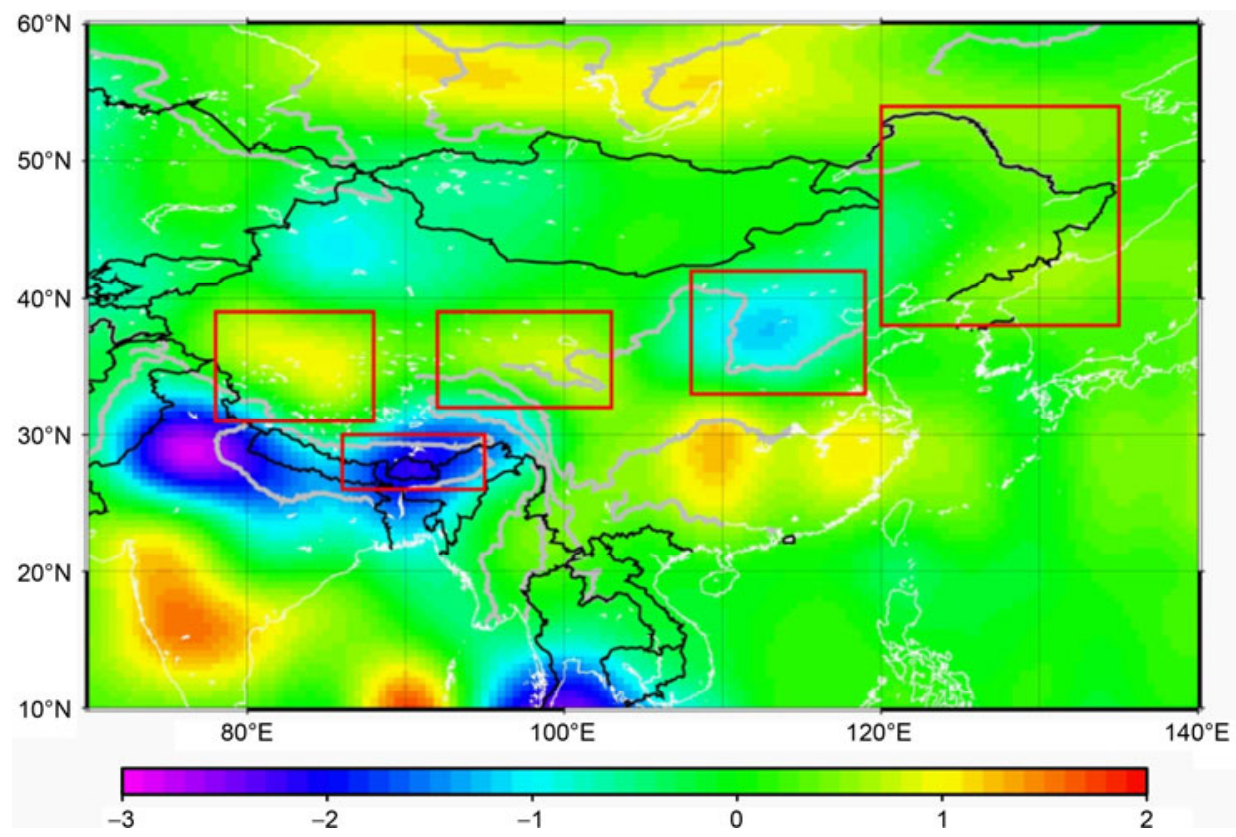

Figure 6 Rate of surface quality change from January 2003 to December 2010 in China (cm/a). 
later than other regions, north of the Yangtze River [9-11]. However, precipitation over the past 50 years on the Qinghai-Tibet Plateau has shown no significant change [12].

Affected by rising temperatures, degradation phenomena in the north include a retreating southern permafrost boundary, increased frozen soil depth, and rising alpine permafrost, which has been observed in Northeast China's permafrost regions [13], Tianshan Mountains [14], and on the Tibetan Plateau [15]. A deeper layer of thaw leads to a gradual loss of soil moisture, strengthening evaporation and increasing runoff [16], which in turn causes a withdrawal of wetlands in permafrost areas.

The vast majority of mountain glaciers in China are in its northwest. Rising temperature has caused glacial retreat [17-21] and increased water supply to wetlands in these areas. Thus, there has been an increase and expansion of lakes [22,23], plus growth of inland marshes in the northwest.

Northwest China, especially the Tibetan Plateau, was previously less affected by human behavior. Thus, wetland changes were the combined results of natural environmental factors in the context of climate warming. Wetland changes in the northwest provinces have been significantly different over the past 30 years (Figure 7). There was a substantial reduction of various wetland types in this region before 1990, after which inland lakes and marshes in Tibet tended to grow rapidly. Remote sensing monitoring of principal great lake water levels in China, based on the lake water footprint algorithm [24] and ICESat GLA14 data from 2003 to 2009, shows that the majority of lakes on the Qinghai-Tibet Plateau have rapidly expanded in recent years (Figure 8). However, the water level of several great lakes in southeastern Tibet has continually declined, the same trend as with water quality changes from GRACE data in Figure 6. Rivers and floodplains continue to decline in this region, which is more consistent with natural environmental change. Because rivers in the region just flow through, coupled with
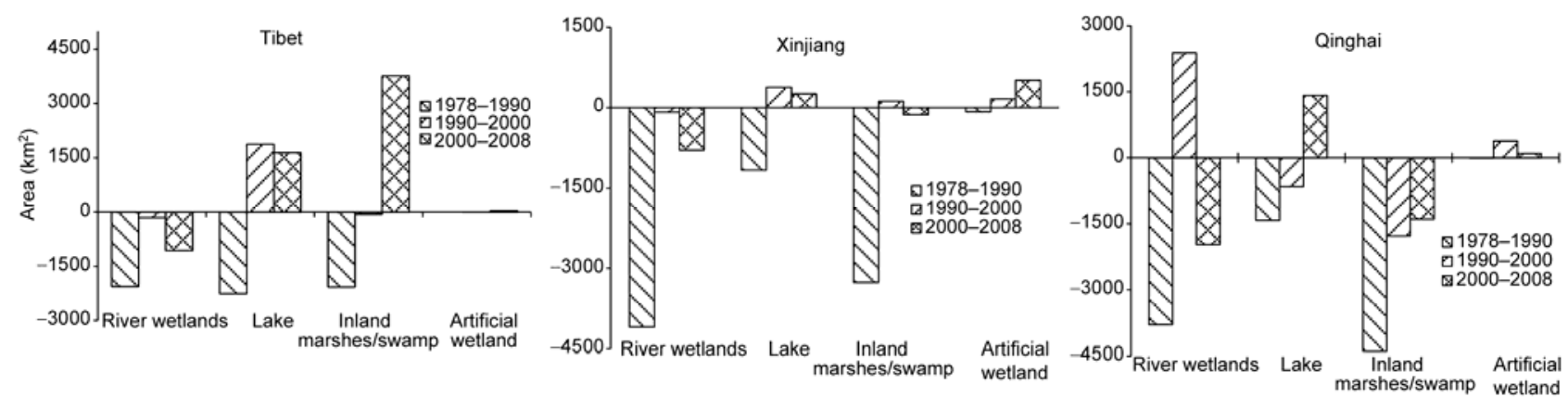

Figure 7 Wetland changes in Tibet, Xinjiang and Qinghai over the past 30 years.

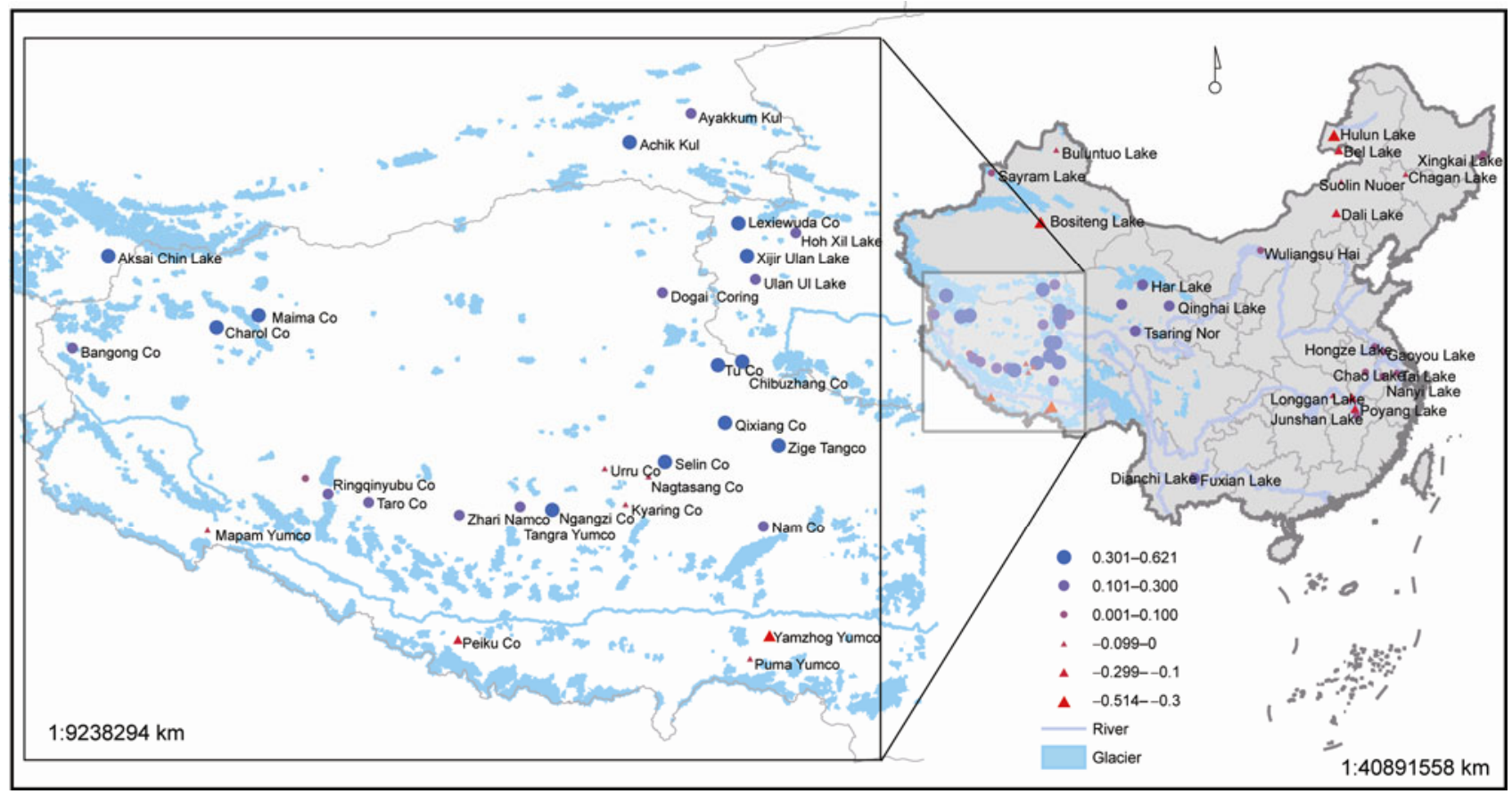

Figure 8 Rate of water level change of principal great lakes in China, from 2003 to 2009 (cm/a). 
increased evaporation from warming, the increased water supply does not contribute to the river wetlands. Thus, there has been continual shrinking of the river wetlands.

Although lakes and inland marshes increased slightly between 1990 and 2000 in Xinjiang, there was a rapid decrease of inland marshes and an increase of artificial wetland areas after 2000. Although the rising temperature produced more meltwater, partially expanding wetlands, areas of wetland in Xinjiang did not appear to enlarge (unlike those in Tibet). This was because of increased arable land [25] and water demand [26], plus direct development of wetlands. This may be explained more quantitatively by the downward trend in earth surface quality between 2003 and 2010 (Figure 6).

The climate warming rate in Qinghai Province is much higher than the global and national rates and there have been small changes in precipitation, according to meteorological data since 1961 [27]. It is the most sensitive area to climate warming in China, and annual evaporation increases every year [28]. Furthermore, increased meltwater caused by rising temperature did not contribute to wetlands in the outflow area of the province (especially near the origin of Three Rivers area). At the same time, increased evaporation from rising temperatures gradually increased water loss. Arable land increase comes at the expense of wetlands [29]. Thus wetlands, especially inland marshes in the province, continued to decline under climate warming, with increased evaporation and snowmelt increasing water outflow, accompanied in part by human development. Lake expansion occurred only in an enclosed basin, reflected by Figure 8 .

\subsection{Relationship between wetlands and agricultural activities}

The direct impact of human activities on wetland is via agriculture. For example, wetland could be directly affected by drainage; it may be degraded by increased irrigation, which substitutes for its function of water supply. These impacts usually occur in densely populated regions.

According to the statistical yearbook, China's arable land has continued to decrease since the 1980s [30], but this has not been uniform throughout the country. Arable land in the northeast and northwest has continually increased, while it has diminished in southeastern developed areas [31]. This phenomenon has the same trend change in total crop area in various provinces since 1949. That is, in economically developed provinces, cultivated land and crop acreage continued to shrink; in less developed and predominantly agricultural provinces, cultivated land and crop acreage continued to expand (Figure 9(a)). Additionally, since 1949 in China, the proportion of paddy fields and irrigated area within arable land continued to increase. The proportion of irrigated land has increased rapidly, especially since the 1970s. Since the 1990 s, the proportion of paddy fields has also dramatically increased [30,31]. According to the statistical yearbook,

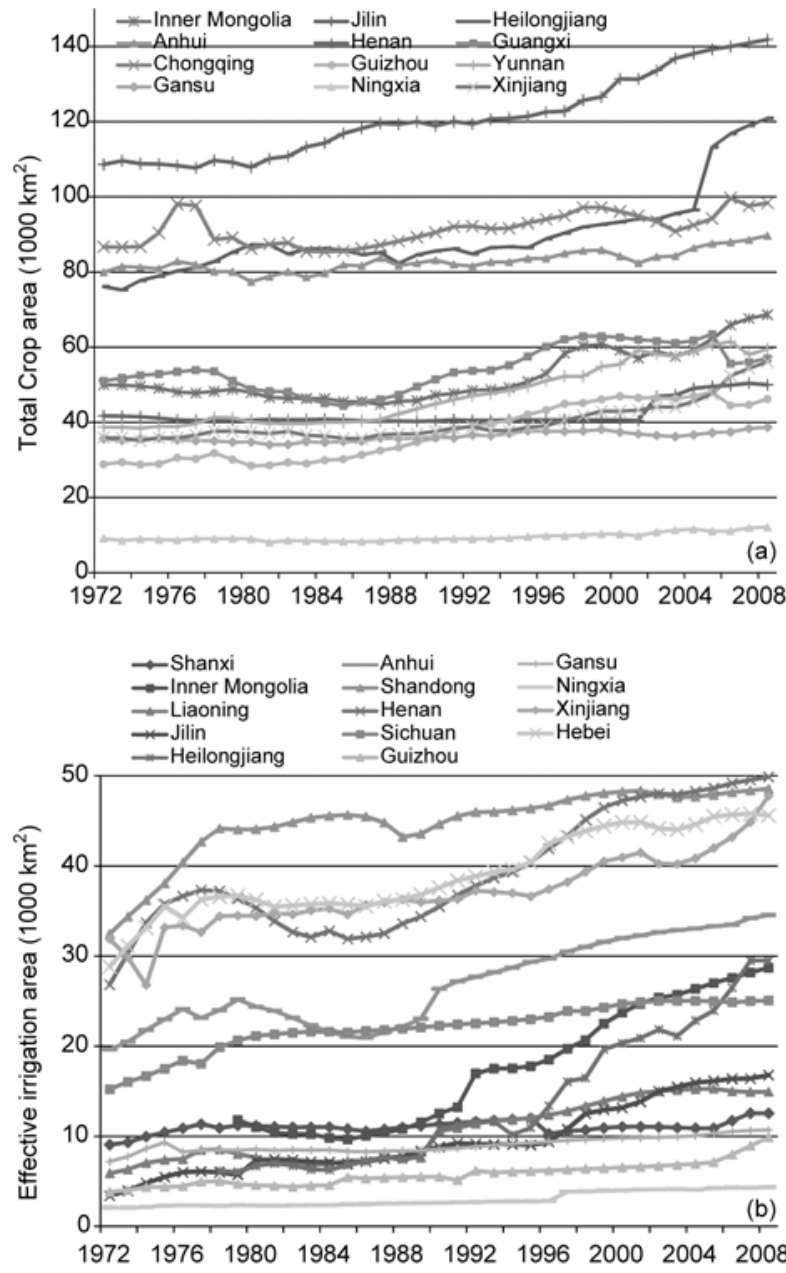

Figure 9 Annual changes of total crop area (a) and effective irrigation area (b) in various provinces, from 1949 to 2009 (from compilation of statistical materials over the last 60 years in China).

in provinces of the northwest and northeast where water resources are limited, effectively irrigated farmland has continued to increase (Figure 9(b)). The increase of irrigated paddy fields inevitably causes an increased demand for water. For any given water resource, wetlands that could provide water resources would decrease. Wetlands would thereby degrade and decrease, especially in north and northwest areas, where the available water resource is less.

Areal changes of arable land in Chinese provinces from the late 1980s to 2000 show that Heilongjiang and Inner Mongolia had the largest increases; among these regions, increases of paddy field area were first and fourth, respectively. For proportion changes from dry land to paddy field area, the three provinces in the northeast (Heilongjiang, Jilin and Liaoning) accounted for $91.9 \%$ of the entire country [31]. The rice field area in Heilongjiang continued to increase since 1980 (Figure 10). The wetland area decrease during this period was also the most dramatic, in particular that of swamp wetland (Figure 11). Thus, there is no doubt that many wetlands have been drained or reclaimed as 


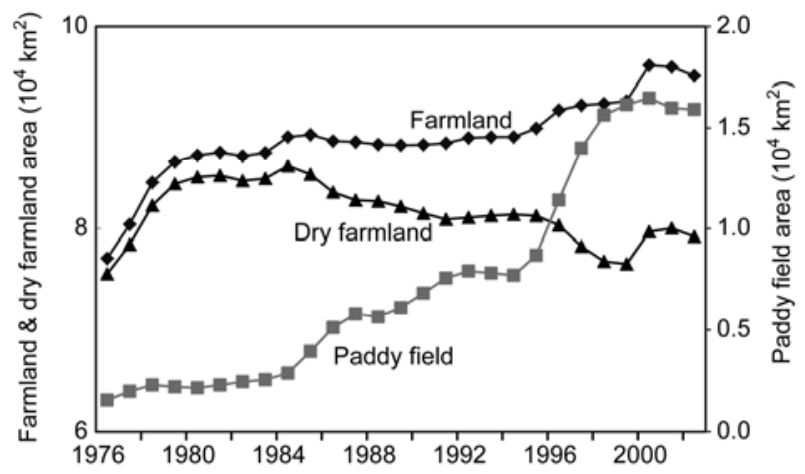

Figure 10 Change of arable land in Heilongjiang.
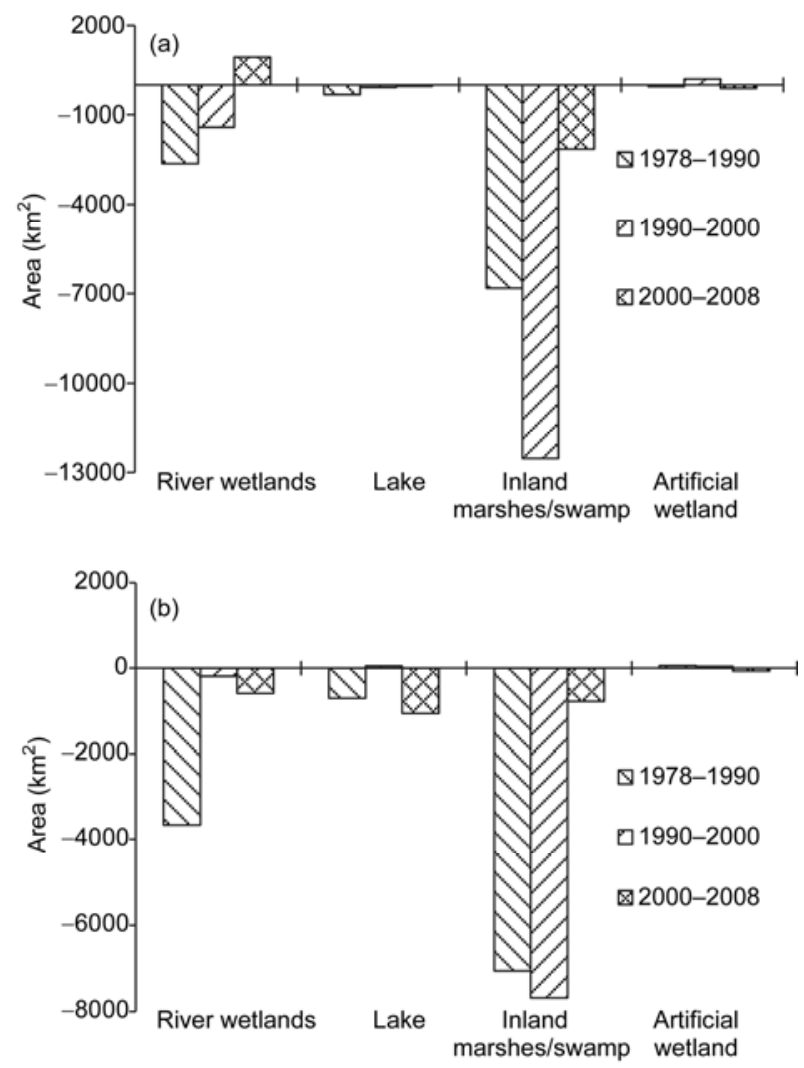

Figure 11 Change in wetland area in Heilongjiang (a) and Inner Mongolia (b).

farmland. This transition competes for water resources, causing the degradation and decrease of wetlands. Additionally, the increase of irrigation facilities would also decrease the water resource supply for wetlands. For example, dams in Heilongjiang Province increased from 93 in 1990 to 414 in 2000, while reservoirs increased from 491 to 609 (Hydrology Statistical Yearbook of China, 1991 and 2001). These increases of irrigation facilities inevitably degrade and decrease river wetlands and related swamp wetland.

In contrast to the rapid decline of natural wetlands, which was caused by agricultural activity, artificial wetland has been constantly increasing. This is especially true in agriculturally developed provinces of eastern China, where arti- ficial wetland like farms, salt fields and canals, have greatly increased. According to the China Agriculture Yearbook, freshwater aquaculture area in China increased by eight times from 1990 to 2000; Shandong, Heilongjiang, Hebei, Fujian, Anhui and Jiangsu increased the most.

\section{Discussion and conclusions}

Based on Landsat MSS images in 1978 and CBERS-CCD images in 2008 across China, four periods of China wetland maps were developed mainly by manual interpretation. Based on these maps, we draw the following conclusions.

(i) There were about $324097 \mathrm{~km}^{2}$ of wetlands in 2008, for which inland marshes/swamp was the most common wetland type; lakes were second. Most wetlands were in Heilongjiang, Inner Mongolia, Qinghai and Tibet, occupying about $55 \%$ of the national wetland area.

(ii) From 1978 to 2008, the national wetland area continually and considerably decreased by about $33 \%$, based on changes to the wetland map. This sharply contrasted with the approximate $122 \%$ increase of artificial wetlands. Inland marshes were the main contributor to the loss of total wetland from 1978 to 2000, whereas riverine and lacustrine wetlands constituted the main wetland loss between 2000 and 2008. The rate of wetland loss fortunately slowed tremendously, from 5523 to $831 \mathrm{~km}^{2} / \mathrm{a}$.

(iii) Among all lost wetlands, the ratio of transition from wetlands to non-wetlands gradually decreased. About $98 \%$ of lost wetlands were transformed to non-wetlands between 1978 and 1990. This ratio decreased to $86 \%$ between 1990 and 2000 , then to $77 \%$ after 2000 .

(iv) All Chinese provinces were divided into three groups, according to patterns of wetland change that could be relevant to driving forces of such change. Wetlands in the northwest (Tibet, Xinjiang and Qinghai) increased significantly, while there were great decreases in the northeast (Inner Mongolia and Heilongjiang). Wetland reductions in other provinces were relatively slight, because the original wetland areas in 1978 there were small.

(v) Climate change is the main background factor affecting wetland, especially that of rising temperature during 1970-2008. However, responses to rising temperature in different provinces varied. In glacial snow areas, more water resources were available to supply wetlands with meltwater; in other areas, there was less water resource available to wetland because of greater evaporation. In areas with frequent human activity, wetlands are mainly affected by agriculture. A combination of these factors impacted wetland dynamics.

There are still many uncertainties in the study of wetland changes, because of the extensive work of national wetland mapping and complex driving factors of wetland change. Specifically:

(i) Because of the vast territory involved, we cannot 
gather remote sensing images for all provinces at a specified time. It is impossible to do so for early years. This study used base years. The time identified here is the base year when remote sensing images were collected. The actual image acquisition time often spans 3-5 years or more (such as 1978). The result is that these images actually reflect wetland changes over periods longer than a specific year.

(ii) The spatial distribution of wetland is dynamic because of the impact of seasonal climates. Interpretations gleaned from the images, which were obtained at a specific time, may provide a general trend, but may not be precise. Remote sensing data from multiple times might address this issue. This should be a key consideration in later wetland mapping.

(iii) Wetland change is essentially affected by climate change and agricultural activity. There are immense differences in natural conditions and socio-economy between different areas of China. This generates greater complexity in the analysis of wetland change. It is more suitable to study wetland change at a watershed level, at which wetlands are affected by natural environmental factors. Additionally, wetland change and its response to the environment (e.g. climate, snow, permafrost, vegetation and soil moisture) also requires further study, which will be attempted in the future.

Many thanks to Professor Jinxing Zhou from the Chinese Academy of Forestry Research for strong cooperation and support during field investigation and verification. Professor Jiancheng Shi from the Institute of Remote Sensing Applications, Chinese Academy of Sciences, and Professor Yongjiu Dai from Beijing Normal University, supported us during data analysis. Academician Xingtu Liu from the Institute of Geography and Agricultural Ecology, Chinese Academy of Sciences, Director Guangren Ma from the State Forestry Administration, and Professor Mingxiang Zhang from Beijing Forestry University, provided very good suggestions. We are grateful for their kind help. This work was supported by the National High-tech R\&D Program of China (2009AA122003).

1 Ramsar Convention Secretariat. About the Ramsar Convention: Why conserve wetlands? 2009

2 Liu H Y. Wetlands Landscape Changes and the Cumulative Effect (in Chinese). Beijng: Science Press, 2005

3 Liu J G, Diamond J. China's environment in a globalizing world. Nature, 2005, 435: 1179-1186

4 Zheng Y M, Zhang H Y, Niu Z G, et al. Protection efficacy of national wetland reserves in Cina. Chin Sci Bull, 2012, 57, doi: 10.1007/s11434-011-4942-9

5 Niu Z G, Gong P, Cheng X, et al. Geographical characteristics of China's wetland derived from remote sensing. Sci China Earth Sci, 2009, 52: 723-738

6 Gong P, Niu Z G, Cheng X, et al. China's wetland change (19902000) determined by remote sensing. Sci China Earth Sci, 2010, 53: 1036-1042

7 David Cyranoski. Putting China's wetlands on the map. Nature, 2009, 458: 134

8 Zhang Z Z, Chao B F, Yang L, et al. An effective filtering for GRACE time-variable gravity: Fan filter. Geophys Res Lett, 2009, 36: doi: 10.1029/2009GL039459
9 Tang H Y, Zhai P M, Wang Z Y. On change in mean maximum temperature, minimum temperature and diurnal range in China during 1951-2002 (in Chinese). Clim Environ Res, 2005, 10: 728-731

10 Lin Z Y, Zhao Y X. Spatial characteristics of precipitation temperature changes in Tibetan Plateau. Sci China Earth Sci, 1996, 26: 354-358

11 Li L, Cun X D, Qin N, et al. Study on temperature variations and its anomaly patterns over Qinghai-Xizang Plateau (in Chinese). Plateau Meteor, 2003, 22: 524-530

12 Ding Y H, Zhang L. Intercomparison of the time for climate abrupt change between the Tibetan Plateau and other regions in China (in Chinese). Chin J Atmos Sci, 2008, 32: 794-805

13 He R X, Jin H J, Lü L Z, et al. Recent changes of permafrost and cold regions environments in the northern part of Northeastern China (in Chinese). J Glaciol Geocryol, 2009, 3: 525-531

14 Zhao L, Liu G Y, Jiao K Q, et al. Variation of the permafrost in the headwaters of the Urumqi River in the Tianshan Mountains since 1991 (in Chinese). J Glaciol Geocryol, 2010, 2: 223-230

15 Nan Z T, Gao Z S, Li S X, et al. Permafrost changes in the northern limit of permafrost on the Qinghai-Tibet Plateau in the last 30 years (in Chinese). Acta Geogr Sin, 2003, 58: 817-823

16 Jin H J, Li S X. Impacts of climatic change on permafrost and cold regions environments in China (in Chinese). Acta Geogr Sin, 2000, 55: $161-173$

17 Wang S J, Zhang M J, Li Z Q. Glacier changes and its response to climate change in Tianshan in past 50 years (in Chinese). Acta Geogr Sin, 2011, 66: 38-46

18 Li Z G, Yao T D, Ye Q H, et al. Monitoring glacial variations based on remote sensing in the Luozha region,eastern Himalayas, 19802007 (in Chinese). Geogr Res, 2011, 5: 939-952

19 Yao T D. Glaciers changes and its impact on lakes in southern Tibetan Plateau (in Chinese). Chin Sci Bull, 2010, 55: 1749

20 Nie Y, Zhang Y L, Liu L. Monitoring of glaciers changes in Qomolangma national nature reserve in recent 30 years (in Chinese). Acta Geogr Sin, 2010, 65: 13-28

21 Cao B, Pan B T, Gao H S, et al. Glacier variation in the Lenglongling range of eastern Qilian Mountains from 1972 to 2007 (in Chinese). J Glaciol Geocryol, 2010, 32: 242-248

22 Lu A X, Yao T D, Wang L H, et al. Study on the fluctuations of typical glaciers and lakes in the Tibetan Plateau using remote sensing (in Chinese). J Glaciol Geocryol, 2005, 27: 784-792

23 Zhang J C, Jiang Q G, Li Y H, et al. Dynamic monitoring and climatic background of lake changes in Tibet based on RS/GIS (in Chinese). J Earth Sci Environ, 2008, 30: 87-94

24 Wang X W, Cheng X, Li Z, et al. Lake water footprints identification from time-series ICESat/GLAS data. IEEE Geosci Remote Sens, 2011, 9: 1-5

25 Chen H, Wu S X, Feng X. Spatial and temporal characteristic of cultivated land in Xinjiang (in Chinese). Prog Geog, 2010, 29: 312-318

26 Zhu H, Jiao G H, Wang Z. Space-time evolution of arable land pattern in Xinjiang in recent 31 years (in Chinese). Agr Res Dry Areas, 2011, 29: 185-190

27 Li H M, Ma Y S, Bai Y F. An analysis of the impact of climate change on vegetation succession in Qinghai Province. J Glaciol Geocryol, 2010, 32: 414-421

28 Zhang G S. Research of climate change and its impact on the environment in Qinghai (in Chinese). Dissertation for Master's Degree. Beijing: China Agricultural University, 2004

29 Guo X J, Duo H R. Cultivated land dynamics and driving forces in Qinghai Lake basin (in Chinese). Qinghai Agr Forest, 2007, 2: 44-46

30 Zhang S G, Qiu J J, Chen Y Q, et al. Spatial-temporal changes of arable land resources in China since 1949 (in Chinese). Sci Technol Rev, 2006, 24: 83-85

31 Zhang G P, Liu J Y, Zhang Z X. Spatial-temporal changes of cropland in China for the past 10 years based on remote sensing. Acta Geogr Sin, 2003, 58: 323-332

Open Access This article is distributed under the terms of the Creative Commons Attribution License which permits any use, distribution, and reproduction in any medium, provided the original author(s) and source are credited. 